\title{
Comparing performance on the Months of the Year Backwards test in hospitalised patients with delirium, dementia, and no cognitive impairment: an exploratory study
}

\author{
Wolfgang Hasemann ${ }^{1,2}$ - $\cdot$ Nikki Duncan ${ }^{2,3} \cdot$ Caoimhe Clarke $^{2,3} \cdot$ Eva Nouzova $^{2} \cdot$ Lisa-Marie Süßenbach $^{2}$. \\ Catriona Keerie $^{4}$. Valentina Assi ${ }^{4}$. Christopher J. Weir ${ }^{4}$. Jonathan Evans ${ }^{5} \cdot$ Tim Walsh $^{6}$. Elizabeth Wilson ${ }^{7}$. \\ Tara Quasim $^{8}$. Duncan Middleton ${ }^{9}$. Alexander J. Weir ${ }^{9}$. Jennifer H. Barnett ${ }^{10}$. David J. Stott ${ }^{3}$. \\ Alasdair M. J. MacLullich ${ }^{2} \cdot$ Zoë Tieges $^{2,11}$
}

Received: 17 March 2021 / Accepted: 19 May 2021 / Published online: 22 June 2021

(c) The Author(s) 2021

\section{Key summary points}

Aim To investigate performance of the Months of the Year Backwards (MOTYB) test in older hospitalised patients with delirium, dementia, and no cognitive impairment.

Findings Half of the patients with delirium (46\%) could not engage with MOTYB compared to only $11 \%$ of patients with dementia without delirium. In patients able to give responses, those with delirium or dementia performed significantly worse than those without cognitive impairment.

Message Our findings show the potential value of analysing response patterns, especially initial engagement, self-correction, and ability to continue to do the task in addition to considering exclusively the capacity to correctly recite the months until July, June or January.

\begin{abstract}
Purpose To investigate performance of the Months of the Year Backwards (MOTYB) test in older hospitalised patients with delirium, dementia, and no cognitive impairment.

Methods Secondary analysis of data from a case-control study of 149 hospitalised patients aged $\geq 65$ years with delirium [with or without dementia $(N=50)$ ], dementia [without delirium $(N=46)$ ], and no cognitive impairment $(N=53)$. Verbatim transcripts of MOTYB audio recordings were analysed to determine group differences in response patterns.

Results In the total sample [median age 85y (IQR 80-88), 82\% female], patients with delirium were more often unable to recite months backward to November $(36 / 50=72 \%)$ than patients with dementia $(21 / 46=46 \% ; p<0.01)$ and both differed significantly from patients without cognitive impairment $(2 / 53=4 \%$; $p$ 's $<0.001) .121 / 149(81 \%)$ of patients were able to
\end{abstract}

Wolfgang Hasemann

Wolfgang.hasemann@felixplatter.ch

1 University Department of Geriatric Medicine FELIX PLATTER Basel, Burgfelderstrasse, 1014055 Basel, Switzerland

2 Geriatric Medicine, Edinburgh Delirium Research Group, Usher Institute, University of Edinburgh, Edinburgh, Scotland, UK

3 Institute of Cardiovascular and Medical Sciences, University of Glasgow, Glasgow, Scotland, UK

4 Edinburgh Clinical Trials Unit, Usher, University of Edinburgh, Edinburgh, Scotland, UK

5 Institute of Health and Wellbeing, University of Glasgow, Glasgow, Scotland, UK
6 Dept of Critical Care Medicine and Centre for Inflammation Research, University of Edinburgh, Edinburgh, Scotland, UK

7 Dept of Critical Care Medicine and Anaesthesia, Royal Infirmary of Edinburgh, Edinburgh, Scotland, UK

8 Anaesthesia, Critical Care and Pain Medicine, University of Glasgow, Glasgow, Scotland, UK

9 Medical Devices Unit, West Glasgow Ambulatory Care Hospital, Glasgow, Scotland, UK

10 Cambridge Cognition Ltd, Cambridge, UK

11 SMART Technology Centre, School of Computing, Engineering and Built Environment, Glasgow Caledonian University, Glasgow, Scotland, UK 
engage with the test. Patients with delirium were more often unable to engage with MOTYB $(23 / 50=46 \%$; e.g., due to reduced arousal) than patients with dementia $(5 / 46=11 \% ; p<0.001)$; both groups differed significantly $(p$ 's $<0.001)$ from patients without cognitive impairment $(0 / 53=0 \%)$. There was no statistically significant difference between patients with delirium $(2 / 27=7 \%)$ and patients with dementia $(8 / 41=20 \%)$ in completing MOTYB to January, but performance in both groups differed $(p<0.001$ and $p<0.02$, respectively) from patients without cognitive impairment $(35 / 53=66 \%)$.

Conclusion Delirium was associated with inability to engage with MOTYB and low rates of completion. In patients able to engage with the test, error-free completion rates were low in delirium and dementia. Recording of engagement and patterns of errors may add useful information to MOTYB scoring.

Keywords Attention $\cdot$ Cognitive dysfunction $\cdot$ Delirium $\cdot$ Dementia $\cdot$ Case-control studies

\section{Abbreviations}

$\begin{array}{ll}\text { AMJM } & \text { Alasdair MacLullich } \\ \text { CC } & \text { Caoimhe Clarke } \\ \text { DS } & \text { David Stott } \\ \text { EN } & \text { Eva Nouzova } \\ \text { LS } & \text { Lisa-Marie Süßenbach } \\ \text { ND } & \text { Nikki Duncan } \\ \text { ZT } & \text { Zoë Tieges } \\ \text { AMT } & \text { Abbreviated Mental Test } \\ \text { DRS-R98 } & \text { Delirium Rating Scale-Revised 98 } \\ \text { MOTYB } & \text { Months of the Year Backward } \\ \text { OMCT } & \text { Short Orientation, Memory and Concentration } \\ & \text { Test } \\ \text { OSLA } & \text { Observational Scale of Level of Arousal } \\ \text { RASS } & \text { Richmond Agitation-Sedation Scale }\end{array}$

\section{Introduction}

MOTYB is a bedside test of cognitive functioning which is very widely used in clinical practice. Its popularity with clinicians stems from its speed of administration, and its accessibility and acceptability to most patients because it does not require any visual or motor capabilities except for speech and no formal testing materials are needed. MOTYB has been used to assess multiple cognitive domains, including attention and concentration [1,2], executive function [3], working memory [4], and central processing speed [5-7].

MOTYB is a part of several delirium assessment tools [6, 8-11]. As a single item screener of delirium MOTYB shows a range of sensitivities (83-95\%) and specificities $(69-94 \%)[12,13]$. Yet there are currently limited data on MOTYB performance deficits in hospitalised patients. In particular, there are few studies that have examined the ability of MOTYB to discriminate among patients with delirium, dementia and normal cognitive functioning [14]. Such data are needed to inform clinicians as to the utility of the MOTYB in detecting delirium in research and clinical practice and to inform scoring instructions.

Current scoring methods for the MOTYB are mostly based on accuracy criteria, that is, either the number of months that patients can recite without error or using correct/incorrect performance to pre-specified cut-offs such as June, July or January $[15,16]$. Other methods include analysis of specific response patterns, for example, omissions of two or more months, repetitions or commissions [17, 18]. The time taken to complete MOTYB has also been used as a performance measure [19]. Yet the extent to which response patterns might differ in delirium or dementia has not been reported.

In the present study, we examined MOTYB scores and response patterns in a case-control study of older hospitalised patients with delirium, dementia, and no cognitive impairment. We hypothesized that patients with delirium (with or without dementia) would show lower scores and show different response patterns than patients with dementia (without delirium) or no cognitive impairment.

\section{Methods}

\section{Design, setting, and participants}

This study is a secondary post hoc analysis. As such these analyses are exploratory and should be considered hypothesis-generating rather than confirming. Data were derived from a case-control study of a software application for detecting attention deficits in delirium, and the recruitment and assessment methods are described in detail in the original study [20]. Briefly, patients were recruited from geriatrics and orthopaedics wards of the Royal Infirmary of Edinburgh and Glasgow Royal Infirmary, Scotland. Potential participants were first identified through consultation with the clinical care team. Patients were included if they were aged 65 years and above.

Cases and controls were frequency-matched by age within 10-year age bands and sex. Three groups of patients were recruited: patients with delirium (with or without dementia), patients with a diagnosis of dementia (without delirium), and patients without cognitive impairment. Exclusion criteria were visual or hearing impairments severe enough to preclude testing, non-fluent English speakers 
and photosensitive epilepsy. The study was approved by the Scotland A Research Ethics Committee.

\section{Enrolment}

Five researchers, all psychology graduates, carried out the recruitment and assessment of participants (ND, CC, LS, $\mathrm{EN}$, and ZT). The researchers were fully trained in the use of all cognitive assessments and applying the Diagnostic and Statistical Manual of Mental Disorders-5 (DSM-5) criteria [21]. Written informed consent was obtained from patients with sufficient capacity to understand their involvement in the study. In the case of insufficient capacity, an appropriate legal proxy was contacted to provide informed consent.

\section{Assessments and participant groupings}

The reference standard assessment for delirium based on DSM- 5 criteria was informed by the Delirium Rating Scale-Revised 98 [DRS-R98 [22]]. As part of the assessment several scales and cognitive tests were administered: The Observational Scale of Level of Arousal [OSLA, [23]], the Richmond Agitation-Sedation Scale [RASS [24]], the Short Orientation, Memory and Concentration Test [OMCT [25]] and the Abbreviated Mental Test [AMT10 [26]], MOTYB, Days of the Week Backwards, Counting Backwards from 20 to 1, and Digit Span [20].

The following process for MOTYB was used. Patients were asked to recite the months of the year in backwards order starting with December. Task instructions were repeated once if the participant did not understand the task or if they started reciting the months of the year forward. No further prompts were allowed. Responses to MOTYB were recorded and transcribed (see below). Patients who were unable to engage meaningfully with MOTYB due to severe cognitive impairment and/or disturbances in arousal (as judged by the researchers) were retained for the analysis.

Patients were classified as having dementia through either a prior formal clinical diagnosis of dementia, or if they met DSM-IV criteria for dementia (using information from case notes and informants) as determined by a consultant geriatrician [27].

Patients for whom an OMCT score $>20$ was obtained and who did not have an acute change from baseline or a diagnosis of dementia were grouped as having no cognitive impairment.

Using the above assessments, including MOTYB test results, participants were categorized into three groups: delirium according to DSM-5 diagnostic criteria (with or without dementia), dementia (without delirium), or no cognitive impairment. When grouping was unclear, a decision was sought in discussion with experienced geriatricians (AMJM and DS). When participants could not be classified into one of the predefined clinical groups, a patient was declared as indeterminate and excluded from the analysis.

\section{MOTYB transcript analysis}

The five researchers who carried out the recruitment and assessment of participants (ND, CC, LS, EN, and ZT) audiorecorded the MOTYB task. To reduce bias during the transcription process recordings were transcribed blindly by a second researcher who had not carried out the reference standard assessment battery and was not aware of the categorization of the participant. Researcher ND then assessed all transcripts blind to the categorizations and recorded the type of errors made.

Based on the framework used by Meagher et al. [7], the following responses were considered errors: omissions, commissions in the wrong place, non-relevant commissions and repetitions. Following inspection of the transcripts, we added the following response patterns: self-corrections, reciting the months forward, stopping part way through the task and not being able to meaningfully engage with the task (see online Table 1 for examples).

\section{Statistical analysis}

Descriptive and inferential statistical analyses were conducted using IBM SPSS Statistics version 22 (IBM, Inc., Chicago, IL). Fisher's exact tests and Mann-Whitney $U$ tests were used to analyse group differences. Holm-Bonferroni corrections were applied to account for multiple comparisons [28].

\section{Results}

\section{Participants}

From 187 hospitalised older patients, 170 MOTYB audio recordings were available. From the initial sample of 170 patients with MOTYB recordings, 21 patients were grouped as indeterminate and were excluded from further analysis. The analysis dataset for this study thus consisted of 149 patients: 50 patients with delirium, 46 patients with dementia, and 53 patients without cognitive impairment (Online-Fig. 1).

Patients were aged between 67 and 98 years (median 85 years, inter-quartile range (IQR) $80-88$ ). Patients without cognitive impairment (median 82 years, IQR 76-85) were younger compared to patients with dementia (median 85 years, IQR $82-89 ; U=-3.640, p<0.001)$ and patients with delirium (with or without dementia) (median 87 years, IQR 83-90; $U=-4.194, p<0.001)$. Delirium and dementia groups did not differ in age $(U=-0.889, p=0.374)$. 
Table 1 Patient characteristics

Total Delirium (with or without pre- Dementia (no delirium) No cognitive impairment existing cognitive impairment)

\begin{tabular}{lllll}
\hline$N$ & 149 & 50 & 46 & 53 \\
Age median (IQR) & $85.0(80.0 ; 88.0)$ & $87.0(82.5 ; 90.0)^{* *}$ & $85.0(82,089.0)^{* *}$ & $82.0(76.0 ; 85.0)$ \\
Gender female (\%) & $122(81.9)$ & $39(78.0)$ & $35(76.1)$ & $48(90.6)$ \\
CCI & $3.0(2.0 ; 5.0)$ & $4.0(2.0 ; 5.0)$ & $3.0(2.0 ; 5.0)$ & $3.0(1.0 ; 4.25)$ \\
Short OMCT (score) (median, IQR) & $11(3-25)$ & $3(0-6)^{* *}$ & $6(2.25-12)^{* *}$ & $26(23.5-28)$ \\
Normal $(N, \%)$ & $(n=144)$ & $(n=47)$ & $(n=44)$ & $(n=53)$ \\
Minimal cognitive impairment $(N, \%)$ & & $2(4 \%)$ & $4(9 \%)$ & $52(98 \%)$ \\
Severe cognitive impairment (N, \%) & & $7(15 \%)$ & $15(34 \%)$ & $1(2 \%)$ \\
& & $38(81 \%)$ & $25(57 \%)$ & $9(8-10)$ \\
AMT10 (score) (median, IQR) & $5(2-8)$ & $1(0-4)^{* *}$ & $3(2-6)^{* * \dagger}$ & $(n=53)$ \\
& $(n=140)$ & $(n=45)$ & $(n=42)$ & $6(6-7)$ \\
Brief Attention Test (score) (median, & $4(3-6)$ & $2.5(0-4)^{* *}$ & $(n=44)$ & $(n=51)$ \\
IQR) & $(n=141)$ & $(n=46)$ & $9(6-12)^{* * \dagger}$ & $1(0-1)$ \\
DRS-R98 total (score) (median, IQR) & $8(1-18)$ & $20(16-23)^{* *}$ & $(n=45)$ & $(n=53)$ \\
& $(n=147)$ & $(n=49)$ & $8(6-11)^{* * \dagger}$ & $1(0-1)$ \\
DRS-R98 severity (score) (median, IQR) & $7(1-13.75)$ & $16(11-19)$ & $(n=45)$ & $(n=53)$ \\
& $(n=148)$ & $(n=50)$ & $0(0-1)^{* * \dagger}$ & $0(0-0)$ \\
OSLA (score) (median, IQR) & $0(0-2.5)$ & $4(2-6)^{* *}$ & $(n=46)$ & $(n=53)$ \\
& $(n=149)$ & $(n=50)$ & & \\
\hline
\end{tabular}

IQR Inter-quartile range, CCI Charlson Comorbidity Index [32]

Short OMCT Short Orientation-Memory-Concentration Test (score range 0-28). Short OMCT categories: severe cognitive impairment (score 0-8), minimal impairment (score 9-20), normal (score $>20$ )

AMT10 Abbreviated Mental Test-10 (score 0-10, score $\leq 7$ indicates cognitive impairment). The Brief Attention Test comprises digit span (3 forward trials, 2 backward trials), months of the year backward and days of the week backward (total score range 0-7, score $<5$ indicates attention impairment)

DRS-R98 Delirium Rating Scale-Revised 98 (total score range 0-46 and severity sub-score range 0-39, higher scores indicate increased likelihood and severity of delirium)

OSLA Observational Scale of Level of Arousal (score range 0-15, higher scores indicate more abnormal level of arousal, incorporating both reduced and increased arousal)

**Significantly different to cognitively unimpaired patients at $p<0.003$ level after Holm-Bonferroni correction [28]

${ }^{\dagger}$ Significantly different to patients with delirium at $p<0.003$ level after Holm-Bonferroni correction [28]

Table 2 Worse performance in MOTYB

\begin{tabular}{|c|c|c|c|c|c|c|c|c|c|}
\hline \multirow{3}{*}{$N=149$} & \multirow{2}{*}{\multicolumn{2}{|c|}{$\begin{array}{l}\text { Delirium } \\
N=50\end{array}$}} & \multirow{2}{*}{\multicolumn{2}{|c|}{$\begin{array}{l}\text { Dementia } \\
N=47\end{array}$}} & \multirow{2}{*}{\multicolumn{2}{|c|}{$\begin{array}{l}\text { No cogni- } \\
\text { tive impair- } \\
\text { ment } \\
N=53\end{array}$}} & \multirow{3}{*}{$\begin{array}{l}\text { Delirium vs dementia } \\
p\end{array}$} & \multirow{3}{*}{$\begin{array}{l}\text { Delirium vs No cog- } \\
\text { nitive impairment } \\
p\end{array}$} & \multirow{3}{*}{$\begin{array}{l}\text { Dementia vs No } \\
\text { cognitive impair- } \\
\text { ment } \\
p\end{array}$} \\
\hline & & & & & & & & & \\
\hline & $n$ & $\%$ & $n$ & $\%$ & $n$ & $\%$ & & & \\
\hline Not meaningfully engage & 23 & 46 & 5 & 11 & 0 & & $<0.001 * *$ & $<0.001^{* *}$ & $0.02 *$ \\
\hline Not able to recite to December & 26 & 52 & 7 & 15 & 0 & & $<0.001 * *$ & $<0.001 * *$ & $0.004 * *$ \\
\hline December last correct month & 36 & 72 & 21 & 45 & 0 & & $0.012 *$ & $<0.001^{* *}$ & $<0.001 * *$ \\
\hline
\end{tabular}

Fisher exact test analyses for delirium versus dementia, delirium versus no cognitive impairment and dementia versus no cognitive impairment

*Lost significance with Holm-Bonferroni correction

**Significant with Holm-Bonferroni correction [28]

The majority of patients (122/149) were female [82\% (Table 1)].

\section{Group comparisons of response patterns in patients}

In the total analysis sample of 149 patients, more patients with delirium $(36 / 50=72 \%)$ than patients with dementia 
$(21 / 46=46 \%$; $(p=0.01)$ were unable to state that November was the month before December (Table 2). Both groups differed significantly from patients without cognitive impairment $(2 / 53=4 \%, p$ 's $<0.001)$.

More patients in the delirium group $(26 / 50=52 \%)$ than in the dementia group $(7 / 47=15 \%)$ were unable to start the MOTYB by stating December as the first correct month $(p<0.001)$, and both groups differed from patients without cognitive impairment $(0 / 53=0 \%, p<0.001$ and $p<0.004$, respectively) (Table 2 ).

The median 'last correct month' was "No correct month" (IQR = November, no correct month) in the delirium group, November $(\mathrm{IQR}=$ September, December $)$ in the dementia group and January (IQR = January, May) in the group without cognitive impairment. Patients with delirium stated significantly fewer last correct months than patients with dementia $(U=-3,802, p<0.001)$.

More patients with delirium $(23 / 50=46 \%)$ than patients with dementia $(5 / 46=11 \%)$ were unable to meaningfully engage with MOTYB $(p<0.001$; Table 2$)$ and both groups differed from patients without cognitive impairment $(0 / 53=0 \% ;(p<0.001$ and $p=0.02$, respectively).

121 patients were able to meaningfully engage with MOTYB. Of these, patients with delirium $(2 / 27=7 \%)$ did not differ significantly from patients with dementia $(8 / 41=20 \%)$ in ability to recite the months back to January without error $(p=0.29)$, and both groups differed from patients without cognitive impairment $(35 / 53=66 \%$; $p$ 's $<0.001)$.

Compared to the group without cognitive impairment, patients with delirium and/or dementia more often recited the months forward instead of backward $(p<0.002$ and $p<0.001)$, respectively, stopped part way through $(p<0.001$ and $p<0.001)$, respectively. Stopping part way through was the most powerful discriminator between patients without cognitive impairment (none) and cognitively impaired patients, either due to delirium $(18 / 27=67 \%, p<0.001)$ or dementia $(22 / 41=54 \%, p<0.001)$. There were no significant differences between the delirium and dementia groups in frequency of any of the response patterns. None of the
Table 3 Reciting backwards to January for patients being able to meaningfully engage with MOTYB

\begin{tabular}{|c|c|c|c|c|c|c|c|c|c|}
\hline \multirow{3}{*}{$N=121$} & \multicolumn{2}{|c|}{ Delirium } & \multicolumn{2}{|c|}{ Dementia } & \multicolumn{2}{|c|}{$\begin{array}{l}\text { No } \\
\text { cognitive } \\
\text { impair- } \\
\text { ment }\end{array}$} & \multirow{3}{*}{$\begin{array}{l}\text { Delirium vs } \\
\text { dementia }\end{array}$} & \multirow{3}{*}{$\begin{array}{l}\text { Delirium vs no cog- } \\
\text { nitive impairment } \\
p\end{array}$} & \multirow{3}{*}{$\begin{array}{l}\text { Dementia vs no } \\
\text { cognitive impair- } \\
\text { ment } \\
P\end{array}$} \\
\hline & \multicolumn{2}{|c|}{$N=27$} & \multicolumn{2}{|c|}{$N=41$} & \multicolumn{2}{|c|}{$N=53$} & & & \\
\hline & $N$ & $\%$ & $n$ & $\%$ & $n$ & $\%$ & & & \\
\hline $\begin{array}{l}\text { December } \\
\text { to January }\end{array}$ & 2 & 7 & 8 & 20 & 35 & 66 & 0.29 & $<0.001 * *$ & $<0.001 * *$ \\
\hline
\end{tabular}

Fisher exact test analyses for delirium versus dementia, delirium versus no cognitive impairment and dementia versus no cognitive impairment

**Significant with Holm-Bonferroni correction[28]

Table 4 Comparison of MOTYB response patterns in patients who are able to meaningfully engage with the task $(n=121)$

\begin{tabular}{|c|c|c|c|c|c|c|c|c|c|}
\hline & \multicolumn{2}{|c|}{$\begin{array}{l}\text { Delirium } \\
N=27\end{array}$} & \multicolumn{2}{|c|}{$\begin{array}{l}\text { Dementia } \\
N=41\end{array}$} & \multicolumn{2}{|c|}{$\begin{array}{l}\text { No cognitive } \\
\text { impairment } \\
N=53\end{array}$} & \multirow{2}{*}{$\begin{array}{l}\text { Delirium vs } \\
\text { dementia } \\
p\end{array}$} & \multirow{2}{*}{$\begin{array}{l}\text { Delirium vs no cog- } \\
\text { nitive impairment } \\
p\end{array}$} & \multirow{2}{*}{$\begin{array}{l}\text { Dementia vs no } \\
\text { cognitive impair- } \\
\text { ment } \\
P\end{array}$} \\
\hline & $n$ & $\%$ & $n$ & $\%$ & $n$ & $\%$ & & & \\
\hline \multicolumn{10}{|l|}{ Error types } \\
\hline Omission & 7 & (26) & 4 & (10) & 6 & (11) & 0.10 & 0.12 & 1.00 \\
\hline Commission (in wrong place) & 6 & (22) & 15 & (37) & 7 & (13) & 0.29 & 0.35 & $0.01^{*}$ \\
\hline Commission (non-relevant) & 6 & $(22)$ & 5 & (12) & 0 & (0) & 0.32 & $0.001 * *$ & $0.01^{*}$ \\
\hline Repetition & 5 & (19) & 13 & $(32)$ & 11 & $(21)$ & 0.27 & 1.00 & 0.24 \\
\hline Self-correction & 0 & $(0)$ & 5 & (12) & 6 & (11) & 0.15 & 0.09 & 1.00 \\
\hline Reciting forward & 7 & (26) & 11 & (27) & 1 & (2) & 1.00 & $0.002 * *$ & $<0.001 * *$ \\
\hline Stopping part way through & 18 & (67) & 22 & (54) & 0 & (0) & 0.32 & $<0.001 * *$ & $<0.001 * *$ \\
\hline
\end{tabular}

Fisher exact test analyses for delirium versus dementia, delirium versus no cognitive impairment and dementia versus no cognitive impairment *Lost significance with Holm-Bonferroni correction[28]

**Significant with Holm-Bonferroni correction[28] 
patients with delirium self-corrected their errors, compared to $5(12 \%)$ in the dementia group $(p=0.15)$ and $6(11 \%)$ in the group without cognitive impairment $(p=0.09)$, respectively (Tables 3 and 4).

\section{Discussion}

The main findings of this preliminary study are that half of the patients with delirium (46\%) could not engage with MOTYB compared to only $11 \%$ of patients with dementia without delirium. This suggests that the inability to meaningfully engage with the MOTYB (i.e., not responding at all due to altered arousal or severe inattention) may be a useful indicator of possible delirium. These findings are aligned with previous reports [14, 29-31] that being socalled "untestable" (i.e., not engaging meaningfully with cognitive testing) is strongly associated with delirium, and less with dementia.
In patients able to give responses, those with delirium or dementia performed significantly worse than those without cognitive impairment. There were also differences in response patterns, in that none of the patients without cognitive impairment stopped part way through or made nonrelevant commission errors. However, delirium and dementia patients able to engage with MOTYB did not generally differ in performance or response patterns such as omissions, commissions or reciting forward.

Another difference between delirium and dementia patients was that none of the delirious patients self-corrected during the task. By contrast dementia patients and cognitively unimpaired patients tended to self-correct their errors. This might suggest that to self-correct mistakes requires a level of insight and self-monitoring of performance that could be lacking in people who are experiencing delirium. Additionally, patients with delirium appeared to stop earlier in the task, for example reciting months to November or October and then stop (Fig. 1). Our hypothesis about differences in scores and response patterns between dementia

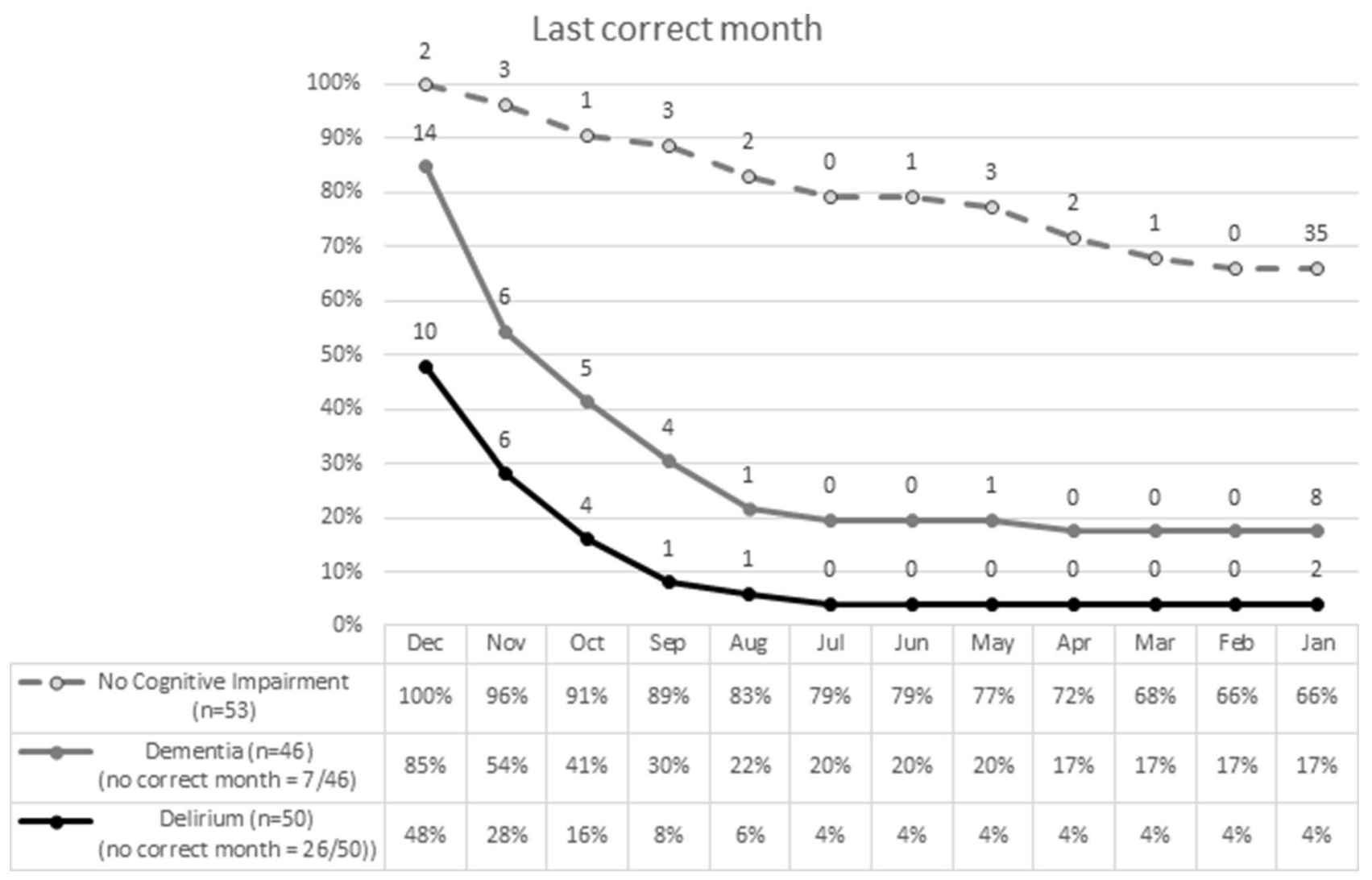

Fig. 1 Last correct month in MOTYB in 149 patients. 2 patients without cognitive impairment, 14 with dementia and 10 with delirium (with and without dementia) stated December as the last correct month in MOTYB. Additionally, out of 50 patients with delirium, 26 could not state December as the last correct month. Of those 3 were able and 23 were unable to meaningfully engage with MOTYB. Out of 46 patients with dementia (without delirium), 7 could not state December as the last correct month. Of those, 2 were able and 5 were unable to meaningfully engage with MOTYB 

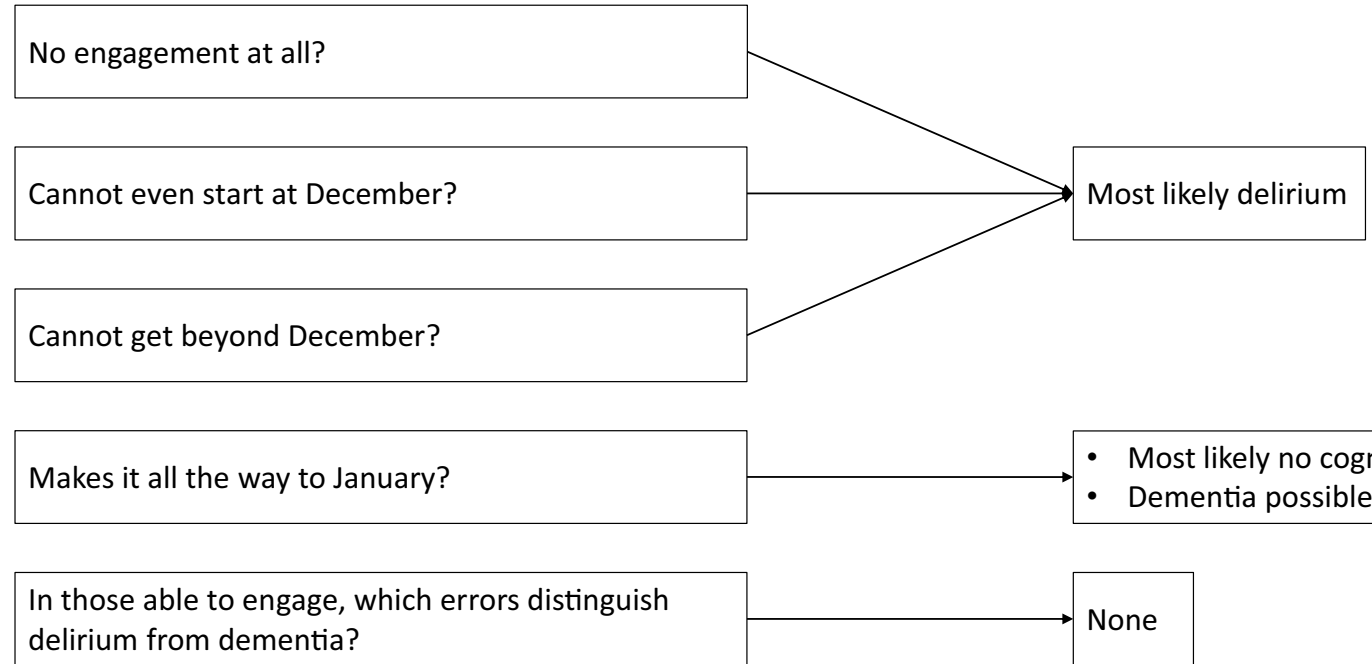

In those able to engage, which errors distinguish dementia from no cognitive impairment?

Fig. 2 Flow chart synthesising the clinical approach from Fig 1 and Tables 2-4

and delirium groups was only true for the number of recited correct months and being able to meaningfully engage with MOTYB. We did not differentiate between delirium with and without dementia in our study, and hence we cannot rule out that there might have been differences in MOTYB test performance between these two groups. Our reason for grouping delirious patients with and without dementia together was that the majority of older patients with delirium have a degree of pre-existing cognitive impairment or (often undiagnosed) dementia, but one cannot exclude with certainty undiagnosed chronic cognitive impairment in the presence of delirium (Fig. 2).

Our findings show the potential value of analysing response patterns, especially initial engagement, self-correction, and ability to continue to do the task in addition to considering exclusively the capacity to correctly recite the months until July, June or January [7]. Adapting MOTYB scoring to incorporate inability to engage in addition to a 'correct/incorrect' classification may add useful clinical information. Indeed, in the 4AT tool the 'untestable' category for the MOTYB component contributes to a possible delirium positive score [6].

This study has several limitations that should be acknowledged. The numbers of patients making individual specific errors was generally small, and some analyses were underpowered. Patients with delirium tended to stop earlier, thereby limiting the number of errors that could be produced. Participants were drawn from a case-control study in which researchers selected patients belonging to predefined clinical groups. This may overestimate the accuracy of the test performance results. We found statistically significant group differences in age despite matching on age bands, which suggests that the 10-year age bands may have been too wide. The researchers who administered MOTYB participated in the initial classification of these patients and MOTYB was used as part of the reference assessment which informed the final diagnostic grouping. This lack of blinding limits the conclusions of the present study. Due to the study design, we were unable to assess patients prior to delirium onset nor did we have pre-existing results from cognitive tests, which meant that the dementia severity of the patients with delirium and dementia was not known. Thus, we neither graded the severity of dementia nor did we differentiate between delirium with and without dementia. The findings can thus be considered preliminary and potentially informative for future more rigorous studies utilising independent, blinded assessments. Such studies could include assessment of diagnostic test accuracy (sensitivity, specificity, etc.) of the MOTYB on its own or in combination with other assessments.

This study also has several strengths. We recruited hospitalised patients representative of those who commonly undergo delirium assessments. Participant groupings were established using a reference standard with explicit operationalised diagnostic criteria incorporating neuropsychological testing, observational scales and a detailed delirium assessment instrument, the DRS-R98. With respect to the MOTYB analyses, we used an objective method of assessing response patterns based on verbatim transcripts. 
These preliminary findings suggest that being unable to engage with MOTYB may have value as a possible indicator of delirium. Additionally, stopping early in the test may also be an indicator of delirium. These findings suggest that going beyond simple scoring thresholds may add to the clinical and research utility of the MOTYB. Future studies involving independent assessments, larger sample sizes, and grading of the severity of dementia patients will be informative and valuable.

Supplementary Information The online version contains supplementary material available at https://doi.org/10.1007/s41999-021-00521-4.

Acknowledgements We acknowledge support from the Medical Research Council (Grant Reference MR/L023210/1), the Biotechnology and Biological Sciences Research Council, the Engineering and Physical Sciences Research Council and the Economic and Social Research Council. Christopher Weir was also supported in this work by NHS Lothian via Edinburgh Clinical Trials Unit.

Author contributions According to the main study authors' contributions are listed in Tieges et. al. [1]. In addition, WH contributed to the analyses and drafted the manuscript in co-work with ZT and AMJM. All authors have reviewed and approved the manuscript.

Funding This work was funded by the Medical Research Council through a Developmental Pathway Funding Scheme, reference MR/ L023210/ 1 (PI: AMJM). AMJM, ZT, DJS, AW, CJW, JB, JE, SP, EJW, TQ and TW acquired the funding. AMJM and ZT are members of the University of Edinburgh Centre for Cognitive Ageing and Cognitive Epidemiology which was funded by the BBSRC and MRC as part of the LLHW (MR/K026992/1). CJW was also supported in this work by NHS Lothian via the Edinburgh Clinical Trials Unit. The funders had no role in study design, data collection and analysis, decision to publish, or preparation of the manuscript.

Data availability On request.

\section{Declarations}

Conflict of interest All authors declare that they have no conflict of interest with this study.

Ethical approval The study was approved by the Scotland A Research Ethics Committee. All procedures performed in this study involving human participants were in accordance with the ethical standards of the local/national research committee and with the 1964 Helsinki declaration and its later amendments or comparable ethical standards.

Informed consent Written informed consent was obtained from patients with sufficient capacity to understand their involvement in the study. In the case of insufficient capacity, an appropriate legal proxy was contacted to provide informed consent.

Open Access This article is licensed under a Creative Commons Attribution 4.0 International License, which permits use, sharing, adaptation, distribution and reproduction in any medium or format, as long as you give appropriate credit to the original author(s) and the source, provide a link to the Creative Commons licence, and indicate if changes were made. The images or other third party material in this article are included in the article's Creative Commons licence, unless indicated otherwise in a credit line to the material. If material is not included in the article's Creative Commons licence and your intended use is not permitted by statutory regulation or exceeds the permitted use, you will need to obtain permission directly from the copyright holder. To view a copy of this licence, visit http://creativecommons.org/licenses/by/4.0/.

\section{References}

1. Meagher D, Leonard M (2018) The active management of delirium: improving detection and treatment. Adv Psychiatr Treat 14(4):292-301. https://doi.org/10.1192/apt.bp.107.003723

2. Blessed G, Tomlinson BE, Roth M (1968) The association between quantitative measures of dementia and of senile change in the cerebral grey matter of elderly subjects. Br J Psychiatry 114(512):797-811. https://doi.org/10.1192/bjp.114.512.797

3. Rudolph JL, Jones RN, Grande LJ, Milberg WP, King EG, Lipsitz LA et al (2006) Impaired executive function is associated with delirium after coronary artery bypass graft surgery. J Am Geriatr Soc 54(6):937-941. https://doi.org/10.1111/j.1532-5415.2006. 00735.x

4. Grober E, Hall CB, Hahn SR, Lipton RB (2011) Memory impairment and executive dysfunction are associated with inadequately controlled diabetes in older adults. J Prim Care Community Health 2(4):229-233. https://doi.org/10.1177/2150131911409945

5. Ball LJ, Bisher GB, Birge SJ (1999) A simple test of central processing speed: an extension of the Short Blessed Test. J Am Geriatr Soc 47(11):1359-1363. https://doi.org/10.1111/j.1532-5415. 1999.tb07440.x

6. Bellelli G, Morandi A, Davis DH, Mazzola P, Turco R, Gentile $S$ et al (2014) Validation of the 4AT, a new instrument for rapid delirium screening: a study in 234 hospitalised older people. Age Ageing 43(4):496-502. https://doi.org/10.1093/ageing/afu021

7. Meagher J, Leonard M, Donoghue L, O'Regan N, Timmons S, Exton C et al (2015) Months backward test: a review of its use in clinical studies. World J Psychiatry 5(3):305-314. https://doi.org/ 10.5498/wjp.v5.i3.305

8. O'Regan NA, Ryan DJ, Boland E, Connolly W, McGlade C, Leonard $\mathrm{M}$ et al (2014) Attention! A good bedside test for delirium? J Neurol Neurosurg Psychiatry 85(10):1122-1131. https://doi.org/ 10.1136/jnnp-2013-307053

9. Hendry K, Quinn TJ, Evans J, Scortichini V, Miller H, Burns J et al (2016) Evaluation of delirium screening tools in geriatric medical inpatients: a diagnostic test accuracy study. Age Ageing 45(6):832-837. https://doi.org/10.1093/ageing/afw130

10. Grossmann FF, Hasemann W, Graber A, Bingisser R, Kressig RW, Nickel CH (2014) Screening, detection and management of delirium in the emergency department-a pilot study on the feasibility of a new algorithm for use in older emergency department patients: the modified Confusion Assessment Method for the Emergency Department (mCAM-ED). Scand J Trauma Resusc Emerg Med 22(1):19. https://doi.org/10.1186/1757-7241-22-19

11. Shenkin SD, Fox C, Godfrey M, Siddiqi N, Goodacre S, Young J et al (2019) Delirium detection in older acute medical inpatients: a multicentre prospective comparative diagnostic test accuracy study of the 4AT and the confusion assessment method. BMC Med 17(1):138. https://doi.org/10.1186/s12916-019-1367-9

12. Fick DM, Inouye SK, Guess J, Ngo LH, Jones RN, Saczynski JS et al (2015) Preliminary development of an ultrabrief two-item bedside test for delirium. J Hosp Med 10(10):645-650. https:// doi.org/10.1002/jhm. 2418

13. Hasemann W, Grossmann FF, Bingisser R, Hafner M, Breil $\mathrm{D}$, Kressig RW et al (2019) Optimizing the month of the year backwards test for delirium screening of older patients in the 
emergency department. Am J Emerg Med 37(9):1754-1757. https://doi.org/10.1016/j.ajem.2019.06.035

14. Leonard M, O'Connell H, Williams O, Awan F, Exton C, O'Connor M et al (2016) Attention, vigilance and visuospatial function in hospitalized elderly medical patients: relationship to neurocognitive diagnosis. J Psychosom Res 90:84-90. https://doi. org/10.1016/j.jpsychores.2016.09.011

15. Ryan DJ, O'Regan NA, Caoimh RO, Clare J, O'Connor M, Leonard $\mathrm{M}$ et al (2013) Delirium in an adult acute hospital population: predictors, prevalence and detection. BMJ Open. https://doi.org/ 10.1136/bmjopen-2012-001772

16. Young CC, Jacobs BA, Clavette K, Mark DH, Guse CE (1997) Serial sevens: not the most effective test of mental status in high school athletes. Clin J Sport Med 7(3):196-198

17. Dubois B, Burn D, Goetz C, Aarsland D, Brown RG, Broe GA et al (2007) Diagnostic procedures for Parkinson's disease dementia: recommendations from the movement disorder society task force. Mov Disord 22(16):2314-2324. https://doi.org/10.1002/ mds. 21844

18. Cunningham EL, Passmore AP, McAuley DF, McGuinness B (2015) Reciting the months of the year backwards: what is a "normal" score? Age Ageing 44(3):537-538. https://doi.org/10.1093/ ageing/afv056

19. Stillman MJ, Rybicki LA (2000) The bedside confusion scale: development of a portable bedside test for confusion and its application to the palliative medicine population. J Palliat Med 3(4):449-456. https://doi.org/10.1089/jpm.2000.3.4.449

20. Tieges Z, Stott DJ, Shaw R, Tang E, Rutter LM, Nouzova E et al (2020) A smartphone-based test for the assessment of attention deficits in delirium: a case-control diagnostic test accuracy study in older hospitalised patients. PLoS ONE 15(1):e0227471. https:// doi.org/10.1371/journal.pone.0227471

21. American Psychiatric Association (2013) Diagnostic and statistical manual of mental disorders. Fifth Edition : DSM-5. 5th edn. American Psychiatric Association, Airlington, VA

22. Trzepacz PT, Mittal D, Torres R, Kanary K, Norton J, Jimerson N (2001) Validation of the Delirium Rating Scale-revised-98: comparison with the delirium rating scale and the cognitive test for delirium. J Neuropsychiatry Clin Neurosci 13(2):229-242. https:// doi.org/10.1176/jnp.13.2.229

23. Tieges Z, McGrath A, Hall RJ, Maclullich AM (2013) Abnormal level of arousal as a predictor of delirium and inattention: an exploratory study. Am J Geriatr Psychiatry 21(12):1244-1253. https://doi.org/10.1016/j.jagp.2013.05.003
24. Sessler CN, Gosnell MS, Grap MJ, Brophy GM, O'Neal PV, Keane KA et al (2002) The Richmond Agitation-Sedation Scale: validity and reliability in adult intensive care unit patients. Am J Respir Crit Care Med 166(10):1338-1344. https://doi.org/10. 1164/rccm.2107138

25. Katzman R, Brown T, Fuld P, Peck A, Schechter R, Schimmel H (1983) Validation of a short Orientation-Memory-Concentration Test of cognitive impairment. Am J Psychiatry 140(6):734-739. https://doi.org/10.1176/ajp.140.6.734

26. Jitapunkul S, Pillay I, Ebrahim S (1991) The abbreviated mental test: its use and validity. Age Ageing 20(5):332-336. https://doi. org/10.1093/ageing/20.5.332

27. American Psychiatric Association (2000) Delirium, dementia, and amnestic and other cognitive disorders. Diagnostic and statistical manual of mental disorders DSM-IV-TR. 4th edn. American Psychiatric Association, Washington, DC, pp 135-147

28. Holm S (1979) A simple sequentially rejective multiple test procedure. Scand J Statist 6(2):65-70

29. Anthony JC, LeResche LA, Von Korff MR, Niaz U, Folstein MF (1985) Screening for delirium on a general medical ward: the tachistoscope and a global accessibility rating. Gen Hosp Psychiatry 7(1):36-42. https://doi.org/10.1016/0163-8343\%2885\% 2990008-8

30. Pendlebury ST, Klaus SP, Thomson RJ, Mehta Z, Wharton RM, Rothwell PM et al (2015) Methodological factors in determining risk of dementia after transient ischemic attack and stroke: (III) applicability of cognitive tests. Stroke 46(11):3067-3073. https:// doi.org/10.1161/STROKEAHA.115.010290

31. Girard TD, Jackson JC, Pandharipande PP, Pun BT, Thompson JL, Shintani AK et al (2010) Delirium as a predictor of long-term cognitive impairment in survivors of critical illness. Crit Care Med 38(7):1513-1520. https://doi.org/10.1097/CCM.0b013e3181 e47be 1

32. Charlson ME, Pompei P, Ales KL, MacKenzie CR (1987) A new method of classifying prognostic comorbidity in longitudinal studies: development and validation. J Chronic Dis 40(5):373-383. https://doi.org/10.1016/0021-9681(87)90171-8

Publisher's Note Springer Nature remains neutral with regard to jurisdictional claims in published maps and institutional affiliations. 